\title{
Etiology and management of dyslipidemia in children with chronic kidney disease and end-stage renal disease
}

\author{
Mona Khurana • Douglas M. Silverstein
}

Received: 4 September 2014 / Revised: 11 February 2015 / Accepted: 16 February 2015 / Published online: 24 March 2015

(C) Springer-Verlag Berlin Heidelberg 2015

\begin{abstract}
Lipids are essential components of cell membranes, contributing to cell fuel, myelin formation, subcellular organelle function, and steroid hormone synthesis. Children with chronic kidney disease (CKD) and end-stage renal disease (ESRD) exhibit various co-morbidities, including dyslipidemia. The prevalence of dyslipidemias in children with CKD and ESRD is high, being present in $39-65 \%$ of patients. Elevated lipid levels in children without renal disease are a risk factor for cardiovascular disease (CVD), while the risk for $\mathrm{CVD}$ in pediatric CKD/ESRD is unclear. The pathogenesis of dyslipidemia in CKD features various factors, including increased levels of triglycerides, triglyceride-rich lipoproteins, apolipoprotein C3 (ApoC-III), decreased levels of cholesterylester transfer protein and high-density lipoproteins, and aberrations in serum very low-density and intermediatedensity lipoproteins. If initial risk assessment indicates that a child with advanced CKD has 2 or more co-morbidities for CVD, first-line treatment should consist of nonpharmacologic management such as therapeutic lifestyle changes and dietary counseling. Pharmacologic treatment of dyslipidemia may reduce the incidence of CVD in children with CKD/ESRD, but randomized trials are lacking. Statins are the only class of lipid-lowering drugs currently approved
\end{abstract}

\section{Khurana}

Center for Drug Evaluation and Research Office of New Drugs Division of Nonprescription Regulation Development, United States Food and Drug Administration, Silver Spring, MD, USA

D. M. Silverstein $(\bowtie)$

Center for Devices and Radiological Health, Division of Reproductive, Gastro-Renal and Urological Devices, Renal Devices Branch, United States Food and Drug Administration, 10903 New Hampshire Avenue Building 66-G252, Silver Spring, MD 20993, USA

e-mail: dsilverstein2001@yahoo.com by the U.S. Food and Drug Administration (FDA) for use in the pediatric population. FDA-approved pediatric labeling for these drugs is based on results from placebo-controlled trial results, showing $30-50 \%$ reductions in baseline low-density lipoprotein cholesterol. Although statins are generally well tolerated in adults, a spectrum of adverse events has been reported with their use in both the clinical trial and postmarketing settings.

Keywords Dyslipidemia · Chronic kidney disease · Cardiovascular disease $\cdot$ Lifestyle change $\cdot$ Dietary counseling $\cdot$ Statin therapy $\cdot$ Adverse events

\section{Lipid abnormalities in CKD-ESRD}

Lipid metabolism and function

Lipids are essential components of cell membranes, contributing to cell fuel, myelin formation, subcellular organelle function, and steroid hormone synthesis. Lipids are generally categorized by their density and other physical characteristics [1]. Since lipids such as cholesterol and triglycerides (TG) are insoluble in plasma, lipoproteins are required to transport all sources (e.g., diet) of lipids to areas in which the lipids can either be stored for future use or used immediately [2], although it should be noted that short- and medium-chain fatty acids also flow via the portal system as fatty acids. Specifically, low-density lipoproteins (LDL) carry the majority of cholesterol (forming LDL-C), while very low-density lipoproteins (VLDL) carry the majority of triglycerides.

The broad categories of lipoproteins are chylomicrons, VLDL, LDL, and high-density lipoproteins (HDL). The major sites of lipoprotein synthesis are the liver and intestine [3]. 
Prevalence and sub-types of dyslipidemia in pediatric chronic kidney disease (CKD) and end-stage renal disease (ESRD)

Children with CKD/ESRD exhibit various co-morbidities, including dyslipidemia. The prevalence of dyslipidemias in children with CKD and ESRD is high (39-65 \%), but is significantly dependent on the cause and vintage of CKD (e.g., usually more common and severe with glomerular disease and proteinuria) and the stage of the disease [4, 5]. The Chronic Kidney Disease in Children (CKiD) study included an assessment of the relationship between renal function and serum lipid levels. The most common type of dyslipidemia was hypertriglyceridemia. They found an inverse relationship between renal function (measured glomerular filtration rate, or GFR) and serum TG and total cholesterol (TC) levels; that is, as GFR declines, TG and TC levels generally increase. Conversely, there is a direct relationship between GFR and HDL-C [4].

The dyslipidemia profile characteristic of pediatric CKD/ ESRD does not include an elevated LDL-C as a prominent or consistent finding. This is noteworthy given that epidemiology studies suggest that LDL are the lipoproteins most relevant to atherosclerosis $[1,2]$. Specifically, children with $\mathrm{CKD} /$ ESRD display aberrations in serum VLDL, intermediatedensity lipoproteins (IDL), and HDL-C. While some of the abnormalities in these indices may recede after renal transplantation, others may persist [6]. In addition, serum TC levels are near normal, while LDL-C levels are variable [7-14].

Impact of dyslipidemia on cardiovascular morbidity and mortality in renal disease

The potential impact of dyslipidemia is profound. Indeed, elevated lipid levels in children without renal disease are a risk factor for hyperlipidemia in adult life and for cardiovascular disease (CVD) [15]. For example, the Pathobiological Determinants of Atherosclerosis in Youth (PDAY) study showed that children with normal renal function may develop fatty streaks during adolescence, which can progress to atheromatous plaques during early adult life [16], and, there is other evidence that children with hypercholesterolemia and diabetes exhibit increased aorta intima-medial thickness and early atherosclerosis [17].

The relative risk for CVD from dyslipidemia in children with CKD and ESRD compared to the general pediatric population is not known due to the short time frame of follow-up and the existence of other CVD risk factors (e.g., inflammation). However, the American Heart Association Expert Panel on Population and Prevention Science has concluded that prevention of CVD in high-risk pediatric patients is warranted due to the higher risk of developing disease as adults [18].

While it is known that children with advanced CKD or ESRD develop atherosclerosis and CVD, it is not clear that clinically relevant CVD occurs in Stage 1 or 2 CKD. Pennisi et al. [19] showed that children with ESRD reveal intimal damage of the coronary arteries. The direct relationship between dyslipidemia and vascular disease is difficult to ascertain due to the small number of patients, concurrent risk factors for vascular disease, the relatively brief period of followup, and the shorter period of CKD.

The mortality rate due to CVD in adults with ESRD is about 10-20-fold higher than the general population [20-22]. However, a definitive role for dyslipidemia in the development of CVD in patients with CKD or on dialysis remains controversial. In a meta-analysis of patients with pre-dialysis CKD, Strippoli et al. studied more than 6,500 patients with $C K D$ and showed that statins significantly reduced serum lipid levels and the incidence of CVD [23]. Similarly, a Cochrane database meta-analysis demonstrated that statins reduced the relative all-cause mortality, and reduced death from CVD by $20 \%$ in more than 18,000 patients with pre-dialysis CKD, with or without CVD [24]. However, a randomized control trial (statins versus control) showed that statins did not decrease all-cause mortality or stroke in patients with CKD due to diabetes [25].

A direct benefit for statins on CVD in patients with ESRD is also unproven. In one placebo, randomized controlled trial (RCT; 4D study) of 1,255 patients (460 evaluable patients who reached the primary endpoint) with ESRD secondary to diabetes, atorvastatin had no effect on CVD events [26]. The study of Heart and Renal Protection (SHARP) trial was a RCT of 9,270 patients with pre-dialysis CKD and ESRD without prior myocardial infarction or coronary revascularization. Patients received a combination of simvastatin plus ezetimibe, or placebo. The follow-up period was 4.9 years, and it showed a significant reduction in major atherosclerotic events, stroke, and arterial revascularization procedures in the treatment group. However, this effect was not observed in ESRD patients alone [27]. The AURORA trial [28] was a RCT that included more than 2,700 patients receiving hemodialysis. Patients received either rosuvastatin or placebo. While rosuvastatin therapy lowered LDL-C, it neither reduced CVD endpoints nor all-cause mortality.

Specific factors involved in the pathogenesis of dyslipidemia in $\mathrm{CKD} / \mathrm{ESRD}$

The pathogenesis of dyslipidemia in CKD involves various factors. These factors have been elegantly and thoroughly discussed in three reviews: $[5,29,30]$.

\section{Triglyceride-rich lipoproteins (TRL)}

In general, the accumulation of triglycerides and TRL in $\mathrm{CKD} / \mathrm{ESRD}$ is due to increased production and impaired catabolism [31]. Indeed, there is strong evidence of reduced 
lipolysis of TRL due to the decreased activity of the major lipases, lipoprotein lipase (LPL) and hepatic triglyceride lipase (HTGL), that are mainly responsible for breaking down TG into free fatty acids [32]. Increased production of TRL may also be secondary to reduced carbohydrate tolerance and enhanced hepatic VLDL synthesis [33]. The reduced fractional catabolic rate is likely due to the decreased activity of two endothelium-associated lipases, LPL and HTGL.

\section{Apolipoprotein C3 (ApoC-III)}

The levels of apoC-III are increased in patients with CKD [34, 35]. Since ApoC-III induces an increase in plasma TG levels [36], this may be an additional factor contributing to dyslipidemia in CKD.

\section{Cholesterylester transfer protein (CETP)}

CETP, also called plasma lipid transfer protein, is expressed in the liver, small intestine, adipose tissue, and spleen [37]. CETP is a substance that binds lipids and transfers them between the lipoproteins. There is evidence that CETP levels are decreased in patients with ESRD $[8,38]$. The impact of decreased CETP levels in ESRD remains controversial.

\section{$H D L-C$}

A reduction in HDL-C levels is due to several factors. First, the relative distribution of HDL subfractions is altered in CKD-ESRD, due mainly to diminished conversion of $\mathrm{HDL}_{3}$ to $\mathrm{HDL}_{2}$. In turn, this results in a reduced capacity of HDL to carry cholesterol into the liver, leading to elevated serum TC levels [39]. The activity of plasma paraoxonase, an enzyme that inhibits the oxidation of LDL, is reduced in patients with $\mathrm{CKD}$, potentially resulting in increased oxidation and reduced activity of HDL-C [40]. In addition, elevated TRL stimulates the conversion of accumulated TG into HDL, whereupon HDL is vulnerable to breakdown by hepatic lipase. Other mechanisms that may play a role in the decline in HDL include reduced lecithin-cholesterol acyltransferase activity [41, 42].

\section{Apolipoprotein A-IV (Apo A-IV)}

Apo-A-IV might protect against atherosclerosis by removing cholesterol from peripheral cells and directing it to the liver and other organs. ApoA-IV plasma levels are considered markers of progression of nondiabetic kidney disease [43]. ApoA-IV levels are reduced in patients with significant proteinuria [44], but increased in dialysis patients [45]. Therefore, Apo-A IV may be protective against dyslipidemia, but this feature may be impaired in patients with glomerular disease in CKD.

\section{$L D L-C$}

As mentioned above, plasma LDL-C levels vary in CKD: they are often elevated in patients with CKD and nephrotic syndrome but normal in patients with CKD due to other causes and in patients with ESRD. However, there may be functional abnormalities in LDL-C in CKD and ESRD. Small dense LDL (sdLDL) is a type of LDL that stimulates the atherosclerotic process. Intermediate-density lipoprotein (IDL) is a metabolite of VLDL that is usually degraded to LDL by HTGL. As mentioned above, there is reduced HTGL activity in CKD, resulting in reduced conversion of IDL to LDL [46]. Taken together, there is accumulation of both sdLDL and IDL in CKD. There is preliminary evidence that sdLDL and IDL may contribute to the development of atherosclerotic plaques [47].

\section{Lipoprotein(a) [Lp(a)]}

Lp(a) consists of Apo(a) covalently bound to an LDL particle. Apo(a) competes with plasminogen for the binding of the proatherosclerotic factors plasminogen receptors, fibrinogen, and fibrin [44]. The Apo(a) gene determines plasma Lp(a) levels. In addition, there is an inverse relationship between the molecular weight or size of Apo(a) isoforms and plasma $\mathrm{Lp}(\mathrm{a})$ levels. In CKD, plasma $\mathrm{Lp}(\mathrm{a})$ levels are also influenced by GFR. In some patients, plasma Lp(a) levels increase early in CKD [48] or in patients without CKD but active nephrotic syndrome [49]. Most people with CKD also exhibit increased or normal levels of ApoB [50].

\section{Nephrotic syndrome}

Nephrotic syndrome (NS) is a common feature of many glomerular diseases affecting children, many of which may progress to CKD. Active NS results in significant proteinuria and hyperlipidemia, the latter featuring elevated TC with or without elevated TG [51, 52]. Specifically, patients with NS exhibit elevated levels of all Apo-B containing lipoproteins, due to reduced catabolism, including VLDL, IDL, LDL-C, and Lp(a); conversely, HDL-C levels are usually normal [53-57]. The pathogenesis includes increased production together with reduced clearance of lipoproteins [54, 58-63]. Specifically, elevation of plasma LDL in NS is thought to be due to increased LDL synthesis and depressed LDL catabolism [52]. Other important changes in NS include elevation of hepatic HMG-CoA reductase and reduction of Ch $7 \alpha$-hydroxylase, the rate-limiting enzyme in cholesterol catabolism [64]. Finally, there is recent evidence of an increase in circulating angiopoietin-like 4 as a compensatory mechanism in patients with nephrotic-range proteinuria in an attempt to reduces the pathology associated with proteinuria, with the unfortunate result of causing hypertriglyceridemia [65]. 
Other specific factors

Insulin resistance, common in CKD and ESRD [66], has been shown to induce abnormalities in lipid metabolism [67] in CKD and ESRD. There are various medications that contribute to dyslipidemia in $\mathrm{CKD} / \mathrm{ESRD}$, including corticosteroids and cyclosporine. Singh et al. measured fasting serum lipid profiles in 73 children, including 21 controls, 25 patients treated with cyclosporine and/or prednisone for glomerular diseases, and 25 patients receiving chronic dialysis. Children receiving combination therapy with cyclosporine and prednisone had higher TC, TG, LDL-C, and VLDL compared to the control group. Similarly, children receiving dialysis had higher TG and VLDL levels than the controls [1]. Finally, intestinal lipoproteins distribute dietary lipid in the postprandial state. In addition, several apolipoproteins are produced by the intestine [68]. The impact of CKD/ESRD on postprandial lipoprotein metabolism is still under study. In studies of patients with $\mathrm{CKD}$, there is a greater rise and an abnormally prolonged increase in circulating triglycerides postprandially $[20,69]$.

\section{Summary}

In summary, the hallmarks of uremic dyslipidemia are hypertriglyceridemia; increased remnant lipoproteins (chylomicron remnants and IDL); reduced HDL cholesterol; and increased sdLDL, Lp(a), and ApoA-IV. Elevated plasma LDL cholesterol level is not typical but can mostly be observed in patients with nephrotic syndrome and peritoneal dialysis (PD) patients.

\section{Etiology of dyslipidemia in renal transplantation}

Many of the risk factors for dyslipidemia mentioned above exist in patients with functioning allografts since CKD naturally occurs in this patient population. Compared to the general population, the rates of CVD are also markedly elevated in renal transplant recipients [70]. The most likely reason for this continued risk is the presence of a degree of CKD in almost all transplant recipients. Indeed, studies in adult renal transplant recipients have revealed that the prevalence of hyperlipidemia initially increases and subsequently decreases, with a prevalence rate of about $30 \%$ up to 5 years after transplantation [71]. In pediatric renal transplant recipients, the prevalence of hypercholesterolemia is about $70 \% 1$ year after transplant, but thereafter declines to $15 \%$ (for TG) and $35 \%$ for TC [72]. The most common pattern of dyslipidemia is an increase in LDL-C and Lp(a) [73].

Other than gradual decline in GFR, there are other factors contributing to dyslipidemia in this patient population. The major culprit is medication use, particularly corticosteroids [74]. Cyclosporine is also associated with dyslipidemia, particularly elevated TC and LDL-C [75]. Interestingly, another calcineurin inhibitor, tacrolimus, is less likely to be associated with dyslipidemia than cyclosporine [76]. Finally, sirolimus is also a risk factor for the development of hyperlipidemia [77].

\section{Targets}

As summarized in the 2013 Kidney Disease: Improving Global Outcomes (KDIGO) [78], the National Institutes of Health (NIH) Expert Panel on Integrated Guidelines for Cardiovascular Health and Risk Reduction in Children and Adolescents in 2011 discussed specific questions of screening for dyslipidemias in children and adolescents and also treatment of dyslipidemias [79]. Serum lipid levels vary depending on age, puberty, and gender. Indeed, serum lipid levels are very low at birth and increase during the first year of life [mean TC of $3.9 \mathrm{mmol} / \mathrm{l}(150 \mathrm{mg} / \mathrm{dl})$, LDL-C $2.6 \mathrm{mmol} / \mathrm{l}(100 \mathrm{mg} / \mathrm{dl})$, and HDL-C $1.4 \mathrm{mmol} / \mathrm{l}(55 \mathrm{mg} / \mathrm{dl})]$ where they remain fairly constant until age 12 and are slightly lower in girls than boys. During puberty, there is a decrease in TC, LDL-C, and a slight decrease in HDL-C in boys. After puberty, TC and LDL-C increase to adult levels in boys and girls. Boys continue to have a slightly lower HDL-C than girls [80]. The NIH Expert Panel on Integrated Guidelines for Cardiovascular Health and Risk Reduction in Children and Adolescents in 2011 published a table displaying acceptable, borderline high and high lipid levels for children and adolescents.

Frequency of measurements

There are no accepted standard guidelines for the measurement of serum lipids in children with CKD or ESRD. It seems logical to assess the levels in any patient with nephrotic syndrome that is unresponsive or only partially responsive to dietary and/or medical therapy, or in any patient with a glomerular disease receiving medications associated with dyslipidemia. If the expected duration of disease or medication exposure is brief, it seems reasonable to defer measurement until a steady level is established. For children and adolescents with established $\mathrm{CKD}$, with or without NS, KDIGO recommends annual measurement of fasting lipids. KDIGO adds that the frequency of annual measurements may require alteration if the clinical circumstances suggest lower or higher risk, or if changes in therapy for dyslipidemia warrant measurement [78].

\section{Management of dyslipidemia in pediatric CKD-ESRD}

Non-pharmacologic management

Initial management in all children with dyslipidemia, regardless of whether they have CKD, should consist of therapeutic 
lifestyle changes (TLC). These changes are intended to ensure growing children receive an adequate amount of nutrients while avoiding excessive dietary fat, increasing physical activities, and limiting sedentary activities. Excess dietary fat restriction as part of a heart-healthy dietary plan such as the Cardiovascular Health Integrated Lifestyle Diet [81] has been shown to reduce total cholesterol and LDL-C, lower the risk of obesity, and decrease insulin resistance in otherwise healthy children without causing adverse effects on growth, development, or nutrition [18]. Evidence that TLC is beneficial in improving clinical outcomes in pediatric CKD is weak, but such measures are unlikely to cause harm and may promote better health. Certain aspects of TLC such as a heart-healthy diet focused on consumption of fat-free milk and water as primary beverages and dietary fat restrictions to $25-30 \%$ of total calories may be possible in otherwise healthy children but not practical in children with CKD who must restrict dietary calcium, phosphorus, or fluid intake or are malnourished. Similarly, increased physical activity may not be feasible if serious metabolic complications of CKD are present. In such cases, disease-specific management becomes particularly important [82], and secondary causes of dyslipidemia should be sought and treated $[81,83]$. Sedentary activities should also be minimized by limiting leisure screen time to less than $2 \mathrm{~h}$ per day in children older than age 2 years and encouraging children older than age 5 years to participate in at least $1 \mathrm{~h}$ of moderate-to-vigorous activity (jogging, baseball) every day and vigorous activity (running, soccer) 3 days per week [18].

\section{Pharmacologic management}

Five classes of lipid-lowering drugs exist and include bile acid sequestrants, cholesterol absorption inhibitors, fibric acid derivatives, 3-hydroxy-3-methyl-glutaryl-CoA
(HMG-CoA) reductase inhibitors or statins, and nicotinic acid (see Table 1). Drugs from only three classes are currently approved by the U.S. Food and Drug Administration (FDA) for use in the pediatric population. The FDAapproved pediatric indications for statins are limited to children and adolescents ages 8-18 years with familial hypercholesterolemia to lower TC, LDL-C, and Apo-B levels in conjunction with diet and lifestyle modifications (see Table 2). FDA-approved pediatric labeling for statins was based on results from placebo-controlled trial results showing 30-50\% reductions in baseline LDL-C regardless of the statin used. The short-term safety of statin therapy in children is based on clinical trials conducted for durations of 2 years or less [84]. These trials have reported asymptomatic elevations in liver transaminases in 1-5 \% of children treated with a statin that reversed upon discontinuation of statin therapy. Ezetimibe is currently the only FDAapproved cholesterol absorption inhibitor indicated to reduce TC and LDL-C in the same pediatric population as statins. This approval was based on a 6-week trial of ezetimibe co-administered with simvastatin using simvastatin monotherapy as the active comparator followed by a 27-week open-label phase. Results at both week 6 and week 33 showed a mean $12 \%$ reduction in TC and $15 \%$ reduction in LDL-C. Colesevelam hydrochloride is a bile acid sequestrant also recently FDA approved for use in boys and post-menarchal girls, age 10-17 years, with heterozygous familial hypercholesterolemia on the basis of a randomized, double-blind, placebo-controlled trial that showed mean reductions in baseline $\mathrm{TC}$ by $12 \%$, in LDL-C by $13 \%$, and in Apo-B by $8 \%$. These trials ranged in duration from 24 weeks to up to 2 years, so the longterm efficacy of using these drugs in children to prevent cardiovascular morbidity and mortality in adulthood has

Table 1 Five classes of lipid-lowering drugs [4]

\begin{tabular}{|c|c|c|}
\hline Lipid-lowering class & Mechanism of action & Effect \\
\hline $\begin{array}{l}\text { Bile acid sequestrants (cholestyramine, } \\
\text { colestipol, colesevelam) }\end{array}$ & $\begin{array}{l}\text { Bind intestinal bile acids to prevent bile acid reuptake in terminal ileum } \\
\text { to lower intrahepatic cholesterol which upregulates LDL receptor } \\
\text { expression and LDL-C clearance }\end{array}$ & $\begin{array}{l}\downarrow \mathrm{TC} \\
\downarrow \text { LDL-C }\end{array}$ \\
\hline Cholesterol absorption inhibitors (ezetimibe & $\begin{array}{l}\text { Prevent absorption of dietary and biliary cholesterol at intestinal brush } \\
\text { border via apparent inhibition of Niemann-Pick C1-like } 1 \text { protein } \\
\text { which lowers intrahepatic cholesterol and upregulates LDL receptor } \\
\text { expression and LDL-C clearance }\end{array}$ & $\downarrow$ LDL-C \\
\hline Fibric acid derivatives & Unclear mechanism but possible $\downarrow$ hepatic TG production & $\begin{array}{l}\downarrow \text { TG } \\
\uparrow \mathrm{HDL}-\mathrm{C}\end{array}$ \\
\hline Statins & $\begin{array}{l}\text { Inhibit 3-hydroxy-3-methyl-glutaryl rate-limiting coenzyme for de novo } \\
\text { cholesterol synthesis }\end{array}$ & $\downarrow$ LDL-C \\
\hline Nicotinic acid (niacin) & $\begin{array}{l}\text { Inhibits hepatic VLDL and, therefore, LDL production } \\
\text { Reduces lipid transfer of cholesterol from HDL to VLDL and delays } \\
\text { HDL clearance }\end{array}$ & $\begin{array}{l}\downarrow \mathrm{TG} \\
\uparrow \mathrm{HDL}-\mathrm{C} \\
\downarrow \text { LDL-C }\end{array}$ \\
\hline
\end{tabular}

$L D L$ low-density lipoproteins, $T G$ triglycerides, $V L D L$ very low-density lipoproteins, $H D L$ high-density lipoproteins 
Table 2 FDA-approved lipid-lowering agents for use in children

\begin{tabular}{llll}
\hline Drug & Pediatric indication & Approval year & Pediatric age group \\
\hline Statins & & & \\
Atorvastatin & HFH & 2002 & $10-17$ years \\
Lovastatin & HFH & 2002 & $10-17$ years; $\geq 1$ year post-menarchal females \\
Pravastatin & HFH & 2002 & $8-13$ years14-18 years \\
Simvastatin & HFH & 2002 & $10-17$ years; $\geq 1$ year post-menarchal females \\
Fluvastatin & HFH & 2006 & $10-16$ years; $>1$ year post-menarchal females \\
Rosuvastatin & HFH & 2009 & $10-17$ years; $\geq 1$ year post-menarchal females \\
Cholesterol absorption inhibitors & & & $10-17$ years; $>1$ year post-menarchal females \\
Ezetimibe & HFH & 2002 & $10-17$ years; $>1$ year post-menarchal females \\
Ezetimibe/simvastatin & HFH & 2004 & $10-17$ years; $>1$ year post-menarchal females \\
Bile Acid Sequestrants & & 2009 & \\
Colesevelam & HFH &
\end{tabular}

$H F H$ heterozygous familial hypercholesterolemia, $L D L$ low-density lipoproteins, $C V D$ cardiovascular disease

FDA-approved pediatric indications for statin use:

HFH with LDL-C $>190 \mathrm{mg} / \mathrm{dl}$ OR HFH with LDL-C $>160 \mathrm{mg} / \mathrm{dl}$ with a positive family history of premature CVD or two or more other CVD risk factors

not been established. Additionally, the long-term safety of these drugs on growth, development, and sexual maturation in children is not known.

When considering the utility of treating dyslipidemia with lipid-lowering drugs in adults or children with CKD or ESRD, it is important to first note that the pathogenesis of vascular endothelial injury in these populations is multi-factorial and may be increasingly governed by non-traditional risk factors, particularly as renal function deteriorates, to which such drugs may not have the same impact as in the non-CKD population. Those with CKD or ESRD develop intimal atherosclerosis similar to the general population for whom the traditional risk factors of hypertension, dyslipidemia, insulin resistance, and obesity play major roles. However, unlike the general population, the $\mathrm{CKD} / \mathrm{ESRD}$ population also develops arteriosclerotic disease with medial calcifications in which nontraditional risk factors unique to the uremic milieu may play a more important role, particularly as CKD progresses [85-87].

Historically, developing a consensus on dyslipidemia management in the CKD population has been challenging, given the unique metabolic complications of CKD, the potentially greater role of non-traditional risk factors in contributing to cardiovascular (CV) disease, and the lack of randomized controlled clinical trials of dyslipidemia treatment in CKD. Extrapolation of results from dyslipidemia trials conducted in the general adult population to children with CKD is not appropriate because the majority of these trials, which showed treatment benefits and prompted recommendations for more aggressive lipid reduction in moderate- to high-risk adults, were secondary prevention trials and do not apply to children and adolescents in whom primary prevention is the treatment goal [84]. Traditionally, primary prevention trials in adults have not definitively shown the benefits of dyslipidemia treatment in reducing the risk of both coronary and total mortality. A more recently conducted primary prevention placebo-controlled trial in 17,802 adults with $\mathrm{C}$-reactive protein levels> $2 \mathrm{mg} / \mathrm{dl}$ and LDL-C less than $130 \mathrm{mg} / \mathrm{dl}$ (the Justification for the Use of Statins in Primary Prevention [JUPITER] trial) showed clear benefit in the statin-treated group for the primary endpoints of nonfatal myocardial infarction, nonfatal stroke, arterial vascularization, hospitalization for unstable angina, and all-cause mortality [88]. However, the study population did not have dyslipidemia, and adults with a serum creatinine higher than $2.0 \mathrm{mg} / \mathrm{dl}$ or other established CKD risk factors such as diabetes and uncontrolled hypertension were excluded from trial entry.

The U.S.-based National Kidney Foundation Kidney Disease Outcomes Quality Initiative (KDOQI) work group published Clinical Practice Guidelines for Managing Dyslipidemias in Chronic Kidney Disease in 2003 and classified CKD as a coronary heart disease (CHD) risk equivalent given the increased risk of $\mathrm{CV}$ disease in the $\mathrm{CKD}$ population compared to the general population. In the absence of randomized controlled clinical trials of dyslipidemia in CKD patients, these guidelines recommended following the 1992 National Cholesterol Education Program guidelines [89] for dyslipidemia goals in adults and adolescents with estimated glomerular filtration rates (eGFR) values of $15 \mathrm{ml} . / \mathrm{min} / 1.73 \mathrm{~m}^{2}$ or greater (formerly known as CKD stages 1 to 4 ) and also recommended treatment in dyslipidemic adults and adolescents with eGFR values below $15 \mathrm{ml} / \mathrm{min} / 1.73 \mathrm{~m}^{2}$ (formerly known as stage 5 CKD) [90]. 
Recognizing that CKD is associated with pathological and/or clinical evidence of coronary disease before the age of 30 years and that multiple prospective studies show childhood lipid and lipoprotein profiles are predictive of future adult lipoprotein profiles with the strongest statistical correlation occurring between late childhood and the third and fourth decades of life [18, 83], two expert pediatric panels published evidence-based guidelines for intensive cardiovascular risk reduction in children with CKD after the 2003 publication of the KDOQI guidelines $[18,78]$. In general, the cardiovascular risk mitigation strategies outlined in these guidelines rely on expert consensus rather than efficacy data, are largely based on the premise that plasma lipid levels in otherwise healthy children are predictive of future plasma lipid levels and subsequent $\mathrm{CV}$ events in adulthood [91-94], and include recommendations for the non-pharmacologic and pharmacologic management of dyslipidemia.

The 2006 Scientific Statement from the American Heart Association (AHA) Expert Panel, endorsed by the American Academy of Pediatrics, states CV risk mitigation strategies are warranted in certain chronic pediatric conditions, including $\mathrm{CKD}$, given the high risk of development of adult-onset CVD. This panel recommended that children with eGFR less than $15 \mathrm{ml} /$ $1.73 \mathrm{~m}^{2}$, on dialysis, or renal transplant recipients should undergo modification of traditional CV risk factors and be monitored for end organ injury with an emphasis on chronic CV risk factor reduction [78]. In addition to disease-specific management, this panel recommended rigorous age-appropriate TLC and smoking cessation as well as optimization of blood pressure, LDL-C, blood glucose, and glycosylated hemoglobin with use of statin therapy in children older than age 10 years to reach the LDL-C goal.

The 2011 National Heart, Blood, Lung Institute (NHLBI) Expert Panel on Integrated Guidelines for Cardiovascular, Health Risk Reduction in Children and Adolescents focused on the promotion of $\mathrm{CV}$ health in all children from birth through young adulthood with an emphasis on preventing risk factor development and prevention of future $\mathrm{CV}$ disease by effective risk factor management [18]. These guidelines identified CKD, ESRD, and post-renal transplant as high-risk conditions for future CV disease and recommended TLC as a firstline treatment if the initial risk assessment indicates that a child with advanced CKD has two or more comorbidities for CVD. The panel did not recommend statin therapy in children under age 10 years with CKD but stated that the potential prevention of adverse CV events may outweigh the risk of statin-related adverse events in males age 10 years or older and post-menarchal females with severely elevated LDL-C and CKD, particularly if they have one or more of the following additional risk factors for CVD [95]:

- Family history of premature coronary disease

- Diabetes

- Hypertension

- Smoking

- ESRD

Since publication of the KDOQI, AHA, and NHBLI guidelines, results from more than a dozen randomized controlled trials, including three landmark trials [88-90], have better informed dyslipidemia management in the adult CKD population and resulted in publication of the 2013 Kidney Disease: Improving Global Outcomes (KDIGO) Clinical Practice Guideline for Lipid Management in CKD [78]. This guideline focuses on lipid management for adults and children with CKD and contains substantial changes in dyslipidemia management in adult CKD from the KDOQI guidelines including the following:

- Treatment escalation with lipid-lowering agents to achieve specific LDL-C targets is not recommended given that LDL-C does not reliably discriminate between those at low versus high $\mathrm{CV}$ risk.

- Higher CV risk rather than elevated LDL-C should be the primary indication to initiate or adjust lipid-lowering treatment.

- The risk of CHD is sufficiently high in adults age 50 years or older with non-dialysis dependent CKD or renal transplant to justify the use of statin or statin/ezetimibe combination.

- Statins or statin/ezetimibe combination should not be initiated in adults with dialysis-dependent CKD due to the uncertain clinical benefits of LDL-C reduction in this population.

Unlike their recommendations for pharmacologic treatment in adults with CKD, the 2013 KDIGO guidelines do not recommend initiation of statins or a stain/ ezetimibe combination in children under 18 years with CKD due to their lack of clear benefit compounded by safety concerns associated with their long-term use in children. Extrapolating results from the recent landmark trials in adults with CKD to children with CKD is not appropriate for several reasons. First, the etiology of CKD in adults is different from that in children. Second, adults with CKD often have co-morbidities that contribute to the dyslipidemia, making them potentially more likely than children to benefit from lipid-lowering treatment. Third, the atherosclerotic lesions targeted by lipid-lowering agents are more likely to be in advanced stages of pathogenesis in adults than in children [85]. 
Sarnak and colleagues recently published (95; online version available only) the KDOQI US Commentary on the 2013 KDIGO Clinical Practice Guideline for Lipid Management in CKD. They note that KDIGO and other (e.g., AHA) guidelines do not recommend using LDL-C as a guide for treatment. Regarding the KDIGO guidelines, the authors state: "The KDIGO guideline did not compare or harmonize their recommendations to other lipid guidelines, which may lead to some confusion among practitioners", and therefore recommended reconciling the various published guidelines. While the majority of the commentary pertains to the treatment of adult patients with $\mathrm{CKD}$, the commentary does highlight the various discrepancies among guidelines for treating children with hyperlipidemia. Specifically, KDIGO does not provide any specific recommendations to treat children with CKD and hyperlipidemia while AHA recommends lifestyle therapy for all patients, with the addition of a statin in those older than ten years of age with LDL-C > $100 \mathrm{mg} / \mathrm{dl}$ and AACE guidelines recommend pharmacotherapy for children older than age 8 years unresponsive to lifestyle changes. In addition, KDOQI suggests further research to better understand the relationship between hyperlipidemia and CVD and developing risk calculators for CVD in children with CKD. They also recommend developing short-term pharmacodynamics and drug safety data in children with CKD, proteinuria or renal transplants. KDOQI agrees with various guidelines that recommend a screening lipid profile in children with recently diagnosed CKD and for those with other conditions such as NS, with annual follow-up assessments. Finally, in children under age 18 years with CKD, KDOQI agrees that there is insufficient evidence to recommend initiation of statins or a combination of statin/ezetimibe; rather, lifestyle changes should be employed for children with CKD and LDL-C >130 mg/dl. However, KDOQI recommends that consideration of underlying renal disease duration and age of onset be considered in the decision of therapy.

Available trials evaluating the efficacy of lipid-lowering drugs in children with CKD are limited to those evaluating the use of statins in children with steroid-resistant nephrotic syndrome (SRNS) [96-98]. Dyslipidemia is a characteristic feature of NS and generally resolves with spontaneous or steroid-induced remission of the disease. However, dyslipidemia can be persistent and severe in steroid-resistant forms where complete remission is not achieved. Given the longstanding nature of childhood SRNS, persistent dyslipidemia in this setting is potentially associated with atherosclerotic complications. At least two autopsy studies have shown evidence of accelerated coronary [99] and renal artery [100] atherosclerosis in dyslipidemic children with NS. These trials showed significant reductions in baseline serum lipid levels after statin treatment, but the results have limited utility for several reasons. The trials were small and uncontrolled. The use of concomitant medications such as angiotensinconverting enzyme inhibitors or corticosteroids, which may have confounded assessment of serum lipid levels, was not consistently specified. Despite their purported pleiotropic effects, the statins had no effect on delaying renal functional deterioration or ameliorating proteinuria. It is also important to note that, despite the significant reduction in baseline serum lipid levels, the mean post-treatment values were not in the normal reference range for the majority of treated children. Surrogate measures of cardiovascular outcomes were not measured in these trials, which were too short in duration to reliably detect such outcomes. Probucol has also been shown to have effects similar to statins for dyslipidemia treatment in childhood SRNS [101], but this drug was removed from the U.S. market in 1995 for safety reasons.

While the 2013 KDIGO guidelines do not recommend statin treatment in children under age 10 years with $\mathrm{CKD}$, the work group acknowledges that statin initiation may be a consideration on a case-by-case basis for boys older than age 10 years and post-menarchal girls with severe LDL-C elevation. This approach is consistent with the 2011 NHBLI guidelines. In such cases, the KDIGO guidelines state the starting dose should be the lowest available dose but caution that no dose escalation trials have been done in children with CKD to confirm the safety of higher statin doses even over the short term and there are no data regarding what the appropriate target for LDL-C should be in children with or without CKD [78]. In addition, clinicians should be aware of several unique concerns to prescribing statin therapy in adolescents. An adolescent who begins statin therapy will receive a higher cumulative dose over the course of their lifetime than most adults, but the safety of such long-term statin exposure beginning in adolescence has not yet been established [84]. Clinical trials in adolescents have not observed adverse effects of statin therapy on growth parameters, hormone synthesis, pubertal development, myopathy, and rhabdomyolysis. However, these trials may have been too short in duration and underpowered to detect such effects. Because statins are potent teratogens, adolescents who are prescribed statin therapy must be educated about effective birth control.

The KDIGO guidelines do not recommend pharmacologic treatment of hypertriglyceridemia to prevent pancreatitis or reduce $\mathrm{CV}$ risk in children with $\mathrm{CKD}$ given the lack of strong evidence that use of drugs such as fibric acid derivatives, niacin, and fish oil are safe and effective. Given the lack of evidence that combination therapy with bile acid sequestrants, colestipol, and ezetimibe in pediatric CKD is safe or effective, the guidelines recommend these multi-drug regimens should be avoided even in children with very elevated LDL-C. 
It is not clear whether pharmacologic treatment of dyslipidemia in children less than age 10 years or those with less advanced CKD may be as safe or effective in reducing the incidence of atherosclerotic $\mathrm{CV}$ disease as in other pediatric populations, and clinicians should carefully consider the risk benefit profile of the short- and long-term use of lipidlowering drugs in these cases [102].

\section{QUESTIONS (answers are provided following the reference list)}

1. Among the following options, a child with chronic kidney disease (CKD) or end-stage renal disease (ESRD) would MOST likely a constellation of abnormalities in lipid profiles is:

\begin{tabular}{llllll}
\hline Option & Serum triglycerides & LDL-C & HDL-C & Apolipoprotein C3 & Lipoprotein(a) \\
A & Increased & Normal & Decreased & Increased & Increased \\
B & Normal & Normal & Decreased & Normal & Decreased \\
C & Increased & Decreased & Increased & Increased & Increased \\
D & Increased & Increased & Increased & Decreased & Normal \\
E & Decreased & Decreased & Increased & Normal & \\
\hline
\end{tabular}

2. The MOST accurate statement regarding cardiovascular disease (CVD) in children with CKD/ESRD who have dyslipidemia is:
A) There is significant evidence that cardiovascular dis- ease is common
B) Atherosclerosis develops early (Stage 1 and 2 CKD) in the course of renal disease
C) Evidence is either lacking or inconclusive regarding the relationship between dyslipidemia and CVD
D) Studies show that children with ESRD have damage limited to the media of the coronary arteries
E) Coronary artery disease is more commonly observed in children versus adults with $\mathrm{CKD} / \mathrm{ESRD}$

3. The MOST accurate statement about dyslipidemia in pediatric renal transplant patients is:
A) Dyslipidemia typically is limited to elevated serum cholesterol
B) The rates of dyslipidemia generally decline in the first year after transplantation
C) There is a proven relationship between dyslipidemia and graft dysfunction
D) The role of medications in the pathogenesis of dys- lipidemia is unproven
E) Dyslipidemia is a proven risk factor for cardiovascu- lar disease

4. For a child with dyslipidemia, the INITIAL approach to therapy should include:
A) Pharmacological therapy with a statin
B) Discontinuation of all medications that may be con- tributing to dyslipidemia
C) Specific lipid-lowering therapy targeting the specific lipid(s) levels that are abnormal

D) Lifestyle change and dietary counseling

E) Referral to a cardiologist to tailor therapy based on cardiological status

5. Among the following, the MOST accurate statement regarding statin therapy for children with or without renal disease is:
A) There are a multitude of randomized, controlled trials showing that the benefits of statin therapy outweigh the risks
B) The most abundant evidence showing the efficacy and safety of statins in children with renal disease is for patients with nephrotic syndrome
C) Several classes of statins have been approved by the Food and Drug Administration
D) For children with CKD, statin therapy is approved for children age 5 years and older
E) Adverse events uncommonly include elevations in liver transaminases

\section{References}

1. Gotto AM Jr, Pownall HJ, Havel RJ (1986) Introduction to the plasma lipoproteins. Methods Enzymol 128:3-41

2. Ginsberg HN (1998) Lipoprotein physiology. Endocrinol Metab Clin North Am 27:503-519

3. Havel RJ, Kane JP (2001) Introduction: structure and metabolism of plasma lipoproteins. In: Scriver CR, Beaudet AL, Sly WS, Valle D (eds) The metabolic and molecular bases of inherited disease, 8th edn. McGraw-Hill, pp 2705-2716

4. Wong CJ, Moxey-Mims M, Jerry-Fluker J, Warady BA, Furth SL (2012) CKiD (CKD in Children) Prospective Cohort Study: a review of current findings. Am J Kidney Dis 60:1002-1011

5. Saland JM, Ginsberg HN (2007) Lipoprotein metabolism in chronic renal insufficiency. Pediatr Nephrol 22:1095-1112 
6. Flynn JT (2006) Cardiovascular disease in children with chronic renal failure. Growth Horm IGF Res 16:84-90

7. Asayama K, Ito H, Nakahara C, Hasegawa A, Kato K (1984) Lipid profiles and lipase activities in children and adolescents with chronic renal failure treated conservatively or with hemodialysis or transplantation. Pediatr Res 18:783-788

8. Asayama K, Hayashibe H, Mishiku Y, Honda M, Ito H, Nakazawa S (1996) Increased activity of plasma cholesteryl ester transfer protein in children with end-stage renal disease receiving continuous ambulatory peritoneal dialysis. Nephron 72:231-236

9. El Bishti M, Counahan R, Jarrett RJ, Stimmler L, Wass V, Chantler C (1977) Hyperlipidaemia in children on regular haemodialysis. Arch Dis Child 52:932-936

10. Mak RH (1998) 1,25-Dihydroxyvitamin D3 corrects insulin and lipid abnormalities in uremia. Kidney Int 53:1353-1357

11. Ohta T, Matsuda I (1985) Apolipoprotein and lipid abnormalities in uremic children on hemodialysis. Clin Chim Acta 147:145-154

12. Papadopoulou ZL, Sandler P, Tina LU, Jose PA, Calcagno PL (1981) Hyperlipidemia in children with chronic renal insufficiency. Pediatr Res 15:887-891

13. Querfeld U, Salusky IB, Nelson P, Foley J, Fine RN (1988) Hyperlipidemia in pediatric patients undergoing peritoneal dialysis. Pediatr Nephrol 2:447-452

14. Zacchello G, Pagnan A, Sidran MP, Ziron L, Braggion M, Pavanello L, Facchin P (1987) Further definition of lipid-lipoprotein abnormalities in children with various degrees of chronic renal insufficiency. Pediatr Res 21:462-465

15. Srinivasan SR, Myers L, Berenson GS (2002) Distribution and correlates of non-high-density lipoprotein cholesterol in children: the Bogalusa Heart Study. Pediatrics 110:e29

16. Strong JP, Malcom GT, McMahan CA, Tracy RE, Newman WP 3rd, Herderick EE, Cornhill JF (1999) Prevalence and extent of atherosclerosis in adolescents and young adults: implications for prevention from the Pathobiological Determinants of Atherosclerosis in Youth Study. JAMA 281:727-735

17. Jarvisalo MJ, Jartti L, Nanto-Salonen $K$, Irjala K, Rönnemaa T, Hartiala JJ, Celermajer DS, Raitakari OT (2001) Increased aortic intimamedia thickness: a marker of preclinical atherosclerosis in high-risk children. Circulation 104:2943-2947

18. Kavey RE, Allada V, Daniels SR, Hayman LL, McCrindle BW, Newburger JW, Parekh RS, Steinberger J (2006) Cardiovascular risk reduction in high-risk pediatric patients: a scientific statement from the American Heart Association Expert Panel on Population and Prevention Science; the Councils on Cardiovascular Disease in the Young, Epidemiology and Prevention, Nutrition, Physical Activity and Metabolism, High Blood Pressure Research, Cardiovascular Nursing, and the Kidney in Heart Disease; and the Interdisciplinary Working Group on Quality of Care and Outcomes Research: endorsed by the American Academy of Pediatrics. Circulation 114:2710-2738

19. Pennisi AJ, Heuser ET, Mickey MR, Lipsey A, Malekzadeh MH, Fine RN (1976) Hyperlipidemia in pediatric hemodialysis and renal transplant patients. Associated with coronary artery disease. Am J Dis Child 130:957-961

20. Foley RN, Parfrey PS, Sarnak MJ (1998) Clinical epidemiology of cardiovascular disease in chronic renal disease. Am J Kidney Dis 32:S112-S119

21. Shoji T, Nishizawa Y, Kawagishi T, Kawasaki K, Taniwaki H, Tabata T, Inoue T, Morii H (1998) Intermediate-density lipoprotein as an independent risk factor for aortic atherosclerosis in hemodialysis patients. J Am Soc Nephrol 9:1277-1284

22. Webb AT, Reaveley DA, O'Donnell M, O'Connor B, Seed M, Brown EA (1995) Lipids and lipoprotein(a) as risk factors for vascular disease in patients on renal replacement therapy. Nephrol Dial Transplant 10:354-357
23. Strippoli GF, Navaneethan SD, Johnson DW, Perkovic V, Pellegrini F, Nicolucci A (2008) Effects of statins in patients with chronic kidney disease: meta-analysis and meta-regression of randomised controlled trials. British Med J 336:645-651

24. Navaneethan SD, Pansini F, Perkovic V, Manno C, Pellegrini F, Johnson DW (2009) HMG CoA reductase inhibitors (statins) for people with chronic kidney disease not requiring dialysis. Cochrane Database Syst Rev 15(2):CD007784

25. Slinin Y, Ishani A, Rector T, Fitzgerald P, MacDonald R, Tacklind J (2012) Management of hyperglycemia, dyslipidemia, and albuminuria in patients with diabetes and CKD: a systematic review for a KDOQI clinical practice guideline. Am J Kidney Dis 60:747-749

26. Wanner C, Krane V, März W, Olschewski M, Mann JF, Ruf G (2005) Atorvastatin in patients with type 2 diabetes mellitus undergoing hemodialysis. N Engl J Med 353:238-248

27. Baigent C, Landray MJ, Reith C, Emberson J, Wheeler DC, Tomson C, Wanner C, Krane V, Cass A, Craig J, Neal B, Jiang L, Hooi LS, Levin A, Agodoa L, Gaziano M, Kasiske B, Walker R, Massy ZA, Feldt-Rasmussen B, Krairittichai U, Ophascharoensuk V, Fellström B, Holdaas H, Tesar V, Wiecek A, Grobbee D, de Zeeuw D, Grönhagen-Riska C, Dasgupta T, Lewis D, Herrington W, Mafham M, Majoni W, Wallendszus K, Grimm R, Pedersen T, Tobert J, Armitage J, Baxter A, Bray C, Chen Y, Chen Z, Hill M, Knott C, Parish S, Simpson D, Sleight P, Young A, Collins R, SHARP Investigators (2011) The effects of lowering LDL cholesterol with simvastatin plus ezetimibe in patients with chronic kidney disease (Study of Heart and Renal Protection): a randomised placebo-controlled trial. Lancet 377:2181-2192

28. Fellström BC, Jardine AG, Schmieder RE, Holdaas H, Bannister K, Beutler J (2009) Rosuvastatin and cardiovascular events in patients undergoing hemodialysis. N Engl J Med 360:1395-1407

29. Saland JM, Ginsberg H, Fisher EA (2002) Dyslipidemia in pediatric renal disease: epidemiology, pathophysiology, and management. Curr Opin Pediatr 14:197-204

30. Kwan BCH, Kronenberg F, Beddhu S, Cheung AK (2007) Lipoprotein Metabolism and Lipid Management in Chronic Kidney Disease. J Am Soc Nephrol 18:1246-1261

31. Batista MC, Welty FK, Diffenderfer MR, Sarnak MJ, Schaefer EJ, Lamon-Fava S, Asztalos BF, Dolnikowski GG, Brousseau ME, Marsh JB (2004) Apolipoprotein A-I, B-100, and B-48 metabolism in subjects with chronic kidney disease, obesity, and the metabolic syndrome. Metabolism 53:1255-1261

32. Cheung AK, Parker CJ, Ren K, Iverius PH (1996) Increased lipase inhibition in uremia: identification of pre-beta-HDL as a major inhibitor in normal and uremic plasma. Kidney Int 49:1360-1371

33. Appel G (1991) Lipid abnormalities in renal disease. Kidney Int 39: $169-183$

34. Moberly JB, Attman PO, Samuelsson O, Johansson AC, KnightGibson C, Alaupovic P (1999) Apolipoprotein C-III, hypertriglyceridemia and triglyceride-rich lipoproteins in uremia. Miner Electrolyte Metab 25:258-262

35. Attman PO, Alaupovic P (1991) Lipid and apolipoprotein profiles of uremic dyslipoproteinemia-relation to renal function and dialysis. Nephron 57:401-410

36. Aalto-Setala K, Fisher EA, Chen X, Chajek-Shaul T, Hayek T, Zechner R, Walsh A, Ramakrishnan R, Ginsberg HN, Breslow JL (1992) Mechanism of hypertriglyceridemia in human apolipoprotein (apo) CIII transgenic mice. Diminished very low density lipoprotein fractional catabolic rate associated with increased apo CIII and reduced apo E on the particles. J Clin Invest 90:1889-1900

37. Drayna D, Jarnagin AS, McLean J, Henzel W, Kohr W, Fielding C, Lawn R (1987) Cloning and sequencing of human cholesteryl ester transfer protein cDNA. Nature 327:632-634

38. Miida T, Miyazaki O, Hanyu O, Nakamura Y, Hirayama S, Narita I, Gejyo F, Ei I, Tasaki K, Kohda Y, Ohta T, Yata S, Fukamachi I, Okada M (2003) LCAT-dependent conversion of prebeta1-HDL 
into alpha-migrating HDL is severely delayed in hemodialysis patients. J Am Soc Nephrol 14:732-738

39. Cheung AK, Wu LL, Kablitz C, Leypoldt JK (1993) Atherogenic lipids and lipoproteins in hemodialysis patients. Am J Kidney Dis 22:271-276

40. Dantoine TF, Debord J, Charmes JP, Merle L, Marquet P, Lachatre G, Leroux-Robert C (1998) Decrease of serum paraoxonase activity in chronic renal failure. J Am Soc Nephrol 9:2082-2088

41. Mekki K, Bouchenak M, Lamri M, Remaoun M, Belleville J (2002) Changes in plasma lecithin: cholesterol acyltransferase activity, HDL(2), HDL(3) amounts and compositions in patients with chronic renal failure after different times of hemodialysis. Atherosclerosis 162:409-417

42. Boes E, Fliser D, Ritz E, Konig P, Lhotta K, Mann JF, Muller GA, Neyer U, Riegel W, Riegler P, Kronenberg F (2006) Apolipoprotein A-IV predicts progression of chronic kidney disease: the mild to moderate kidney disease study. J Am Soc Nephrol 17:528-536

43. Lingenhel A, Lhotta K, Neyer U, Heid IM, Rantner B, Kronenberg MF, Konig P, von Eckardstein A, Schober M, Dieplinger H, Kronenberg F (2006) Role of the kidney in the metabolism of apolipoprotein A-IV: Influence of the type of proteinuria. J Lipid Res 47:2071-2079

44. Kronenberg F, Konig P, Neyer U, Auinger M, Pribasnig A, Lang U, Reitinger J, Pinter G, Utermann G, Dieplinger H (1995) Multicenter study of lipoprotein(a) and apolipoprotein(a) phenotypes in patients with end-stage renal disease treated by hemodialysis or continuous ambulatory peritoneal dialysis. J Am Soc Nephrol 6:110-120

45. Oi K, Hirano T, Sakai S, Kawaguchi Y, Hosoya T (1999) Role of hepatic lipase in intermediate-density lipoprotein and small, dense low-density lipoprotein formation in hemodialysis patients. Kidney Int Suppl 71:S227-S228

46. Best PJ, Hasdai D, Sangiorgi G, Schwartz RS, Holmes DR Jr, Simari RD, Lerman A (1999) Apoptosis. Basic concepts and implications in coronary artery disease. Arterioscler Thromb Vasc Biol 19:14-22

47. Smith EB (1986) Fibrinogen, fibrin and fibrin degradation products in relation to atherosclerosis. Clin Haematol 15:355-370

48. Kronenberg F, Lingenhel A, Lhotta K, Rantner B, Kronenberg MF, Konig P, Thiery J, Koch M, von Eckardstein A, Dieplinger H (2004) The apolipoprotein(a) size polymorphism is associated with nephrotic syndrome. Kidney Int 65:606-612

49. Grutzmacher P, Marz W, Peschke B, Gross W, Schoeppe W (1988) Lipoproteins and apolipoproteins during the progression of chronic renal disease. Nephron 50:103-111

50. Baxter JH, Goodman HC, Havel RJ (1960) Serum lipid and lipoprotein alterations in nephrosis. J Clin Invest 39:455-465

51. Joven J, Villabona C, Vilella E, Masana L, Albertí R, Vallés M (1990) Abnormalities of lipoprotein metabolism in patients with the nephrotic syndrome. N Engl J Med 323:579-584

52. Nakahara C, Kobayashi K, Hamaguchi H, Kanemoto K, Kashiwagi R, Matsui A (1999) Plasma lipoprotein (a) levels in children with minimal lesion nephrotic syndrome. Pediatr Nephrol 13:67-661

53. Garnotel R, Roussel B, Pennaforte F, Randoux A, Gillery P (1996) Changes in serum lipoprotein(a) levels in children with corticosensitive nephrotic syndrome. Pediatr Nephrol 10:699-701

54. Querfeld U, Gnasso A, Haberbosch W, Augustin J, Schärer K (1988) Lipoprotein profiles at different stages of the nephrotic syndrome. Eur J Pediatr 147:233-238

55. Noto D, Barbagallo CM, Cascio AL, Cefalù AB, Cavera G, Caldarella R, Marino G, Travali S, Cutaia I, Maringhini S, Notarbartolo A, Averna M (1999) Lipoprotein(a) levels in relation to albumin concentration in childhood nephrotic syndrome. Kidney Int 55:2433-2439

56. Mocan H, Aksoy A, Uydu HA, Mocan MC (1999) Oxidative damage of erythrocyte membrane in nephrotic syndrome. Pediatr Nephrol 13:326-332
57. Warwick GL, Caslake MJ, Boulton-Jones JM, Dagen M, Packard CJ, Shepherd J (1990) Low-density lipoprotein metabolism in the nephrotic syndrome. Metabolism 39:187-192

58. Warwick GL, Packard CJ, Demant T, Bedford DK, Boulton-Jones JM, Shepherd J (1991) Metabolism of apolipoprotein B-containing lipoproteins in subjects with nephrotic-range proteinuria. Kidney Int 40:129-138

59. Chan MK, Persaud JW, Ramdial L, Varghese Z, Sweny P, Moorhead JF (1981) Hyperlipidaemia in untreated nephrotic syndrome, increased production or decreased removal? Clin Chim Acta 117:317-323

60. Vega GL, Toto RD, Grundy SM (1995) Metabolism of low density lipoproteins in nephrotic dyslipidemia: comparison of hypercholesterolemia alone and combined hyperlipidemia. Kidney Int 47:579586

61. de Sain-van der Velden MG, Kaysen GA, Barrett HA, Stellaard F, Gadellaa MM, Voorbij HA, Reijngoud DJ, Rabelink TJ (1998) Increased VLDL in nephrotic patients results from a decreased catabolism while increased LDL results from increased synthesis. Kidney Int 53:994-1001

62. Vaziri ND (2003) Molecular mechanisms of lipid disorders in nephrotic syndrome. Kidney Int 63:1964-1976

63. Clement LC, Macé C, Avila-Casado C, Joles JA, Kersten S, Chugh SS (2014) Circulating angiopoietin-like 4 links proteinuria with hypertriglyceridemia in nephrotic syndrome. Nat Med 20:37-46

64. Demant T, Mathes C, Gutlich K, Bedynek A, Steinhauer HB, Bosch T, Packard CJ, Warwick GL (1998) A simultaneous study of the metabolism of apolipoprotein B and albumin in nephrotic patients. Kidney Int 54:2064-2080

65. Hager SR (1989) Insulin resistance of uremia. Am J Kidney Dis 14: 272-276

66. Howard BV (1999) Insulin resistance and lipid metabolism. Am J Cardiol 84:28J-32J

67. Singh A, Tejani A (1996) Hyperlipidemia in children: the role of uremia, steroids and cyclosporine therapy. Nephron 74:529-535

68. Charlesworth JA, Kriketos AD, Jones JE, Erlich JH, Campbell LV, Peake PW (2005) Insulin resistance and postprandial triglyceride levels in primary renal disease. Metabolism 54:821-828

69. Weintraub M, Burstein A, Rassin T, Liron M, Ringel Y, Cabili S, Blum M, Peer G, Iaina A (1992) Severe defect in clearing postprandial chylomicron remnants in dialysis patients. Kidney Int 42:12471252

70. Kasiske BL, Umen AJ (1987) Persistent hyperlipidemia in renal transplant patients. Medicine 66:309-316

71. Milliner DS, Morgenstern BZ, Murphy M, Gonyea J, Sterioff S (1994) Lipid levels following renal transplantation in pediatric recipients. Transplant Proc 26:112-114

72. Kasiske BL (1998) Hyperlipidemia in patients with chronic renal disease. Am J Kidney Dis 32:S142-S156

73. Henkin Y, Como JA, Oberman A (1992) Secondary dyslipidemia. Inadvertent effects of drugs in clinical practice. JAMA 267:961-968

74. Ballantyne CM, Podet EJ, Patsch WP, Harati Y, Appel V, Gotto AM Jr, Young JB (1989) Effects of cyclosporine therapy on plasma lipoprotein levels. JAMA 262:53-56

75. Henry ML (1999) Cyclosporine and tacrolimus (FK506): a comparison of efficacy and safety profiles. Clin Transplant 13:209-220

76. Ponticelli C, MacDonald AS, Rajagopalan P, Sindhi R, Mathew T (2001) Phase III trial of Rapamune versus placebo in primary renal allograft recipients. Transplant Proc 33:2271-2272

77. (2013) KDIGO Clinical Practice Guideline for Lipid Management in Chronic Kidney Disease. Kidney Int Supp 3

78. National Heart Lung and Blood Institute (2011) Expert panel on integrated guidelines for cardiovascular health and risk reduction in children and adolescents: summary report. Pediatrics 128(Suppl 5):S213-256 
79. Olson RE (2000) Atherogenesis in children: implications for the prevention of atherosclerosis. Adv Pediatr 47:55-78

80. American Academy of Pediatrics (1992) National Cholesterol Education Program: Report of the Expert Panel on Blood Cholesterol Levels in Children and Adolescents. Pediatrics 89(3 Pt 2):525-584

81. (2003) Kidney Disease Outcomes Quality Initiative G. K/DOQI clinical practice guidelines for management of dyslipidemias in patients with kidney disease. Am J Kidney Dis 41(4 Suppl 3):I-IV, S191

82. Expert Panel on Integrated Guidelines for Cardiovascular Health and Risk Reduction in Children and Adolescents; National Heart, Lung, and Blood Institute (2011). Expert panel on integrated guidelines for cardiovascular health and risk reduction in children and adolescents: summary report. Pediatrics 128 (Suppl 5):S213-256

83. Belay B, Belamarich PF, Tom-Revzon C (2007) The use of statins in pediatrics: knowledge base, limitations, and future directions. Pediatrics 119(2):370-380

84. Tullus K (2012) Dyslipidemia in children with CKD: should we treat with statins? Pediatr Nephrol 27(3):357-362

85. Nogueira J, Weir M (2007) The unique character of cardiovascular disease in chronic kidney disease and its implications for treatment with lipid-lowering drugs. Clin J Am Soc Nephrol 2(4):766-785

86. Shroff R, Degi A, Kerti A, Kis E, Cseprekál O, Tory K, Szabó AJ, Reusz GS (2013) Cardiovascular risk assessment in children with chronic kidney disease. Pediatr Nephrol 28(6):875-884

87. Glynn RJ, Koenig W, Nordestgaard BG, Shepherd J, Ridker PM (2010) Rosuvastatin for primary prevention in older persons with elevated C-reactive protein and low to average low-density lipoprotein cholesterol levels: exploratory analysis of a randomized trial. Ann Intern Med 152:488-496

88. Fellstrom BC, Jardine AG, Schmieder RE, Holdaas H, Bannister K, Beutler J, Chae DW, Chevaile A, Cobbe SM, Grönhagen-Riska C, De Lima JJ, Lins R, Mayer G, McMahon AW, Parving HH, Remuzzi G, Samuelsson O, Sonkodi S, Sci D, Süleymanlar G, Tsakiris D, Tesar V, Todorov V, Wiecek A, Wüthrich RP, Gottlow M, Johnsson E, Zannad F, AURORA Study Group (2009) Rosuvastatin and cardiovascular events in patients undergoing hemodialysis. N Engl J Med 360(14):1395-1407

89. Baigent C, Landray MJ, Reith C, Emberson J, Wheeler DC, Tomson C, Wanner C, Krane V, Cass A, Craig J, Neal B, Jiang L, Hooi LS, Levin A, Agodoa L, Gaziano M, Kasiske B, Walker R, Massy ZA, Feldt-Rasmussen B, Krairittichai U, Ophascharoensuk V, Fellström B, Holdaas H, Tesar V, Wiecek A, Grobbee D, de Zeeuw D, Grönhagen-Riska C, Dasgupta T, Lewis D, Herrington W, Mafham M, Majoni W, Wallendszus K, Grimm R, Pedersen T, Tobert J, Armitage J, Baxter A, Bray C, Chen Y, Chen Z, Hill M, Knott C, Parish S, Simpson D, Sleight P, Young A, Collins R, SHARP Investigators (2011) The effects of lowering LDL cholesterol with simvastatin plus ezetimibe in patients with chronic kidney disease (Study of Heart and Renal Protection): a randomised placebo-controlled trial. Lancet 377(9784):2181-2192

90. Srinivasan SR, Myers L, Berenson GS (2002) Distribution and correlates of non-high-density lipoprotein cholesterol in children: the Bogalusa Heart Study. Pediatrics 110(3):e29
91. Berenson GS, Srinivasan SR, Bao W, Newman WP 3rd, Tracy RE, Wattigney WA (1998) Association between multiple cardiovascular risk factors and atherosclerosis in children and young adults. The Bogalusa Heart Study. New Engl J Med 338(23):1650-1656

92. Magnussen CG, Raitakari OT, Thomson R, Juonala M, Patel DA, Viikari JS, Marniemi J, Srinivasan SR, Berenson GS, Dwyer T, Venn A (2008) Utility of currently recommended pediatric dyslipidemia classifications in predicting dyslipidemia in adulthood: evidence from the Childhood Determinants of Adult Health (CDAH) study, Cardiovascular Risk in Young Finns Study, and Bogalusa Heart Study. Circulation 117(1):32-42

93. Schrott HG, Bucher KA, Clarke WR, Lauer RM (1979) The Muscatine hyperlipidemia family study program. Prog Clin Biol Res 32:619-646

94. (2013) Chapter 4: Pharmacological Cholesterol-Lowering Treatment in Children. Kidney Int Suppl 3:282-283

95. Sarnak MJ, Bloom R, Muntner P, Rahman M, Saland JM, Wilson PFW, Fried L (2014) KDOQI US Commentary on the 2013 KDIGO Clinical Practice Guideline for Lipid Management in CKD. Am J Kidney Dis. doi:10.1053/j.ajkd.2014.10.005

96. Coleman JE, Watson AR (1996) Hyperlipidaemia, diet and simvastatin therapy in steroid-resistant nephrotic syndrome of childhood. Pediatr Nephrol 10(2):171-174

97. Sanjad SA, al-Abbad A, al-Shorafa S (1997) Management of hyperlipidemia in children with refractory nephrotic syndrome: the effect of statin therapy. J Pediatr 130(3):470-474

98. Kano K, Hoshi E, Ito S, Kyo K, Yamada Y, Ando T, Arisaka O, Tomita S, Ueda Y (2000) Effects of combination therapy consisting of moderate-dose intravenous immunoglobulin G, pulsed methylprednisolone and pravastatin in children with steroid-resistant nephrosis. Nephron 84(1):99-100

99. Curry RC Jr, Roberts WC (1977) Status of the coronary arteries in the nephrotic syndrome. Analysis of 20 necropsy patients aged 15 to 35 years to determine if coronary atherosclerosis is accelerated. Am J Med 63(2):183-192

100. Antikainen M, Sariola H, Rapola J, Taskinen MR, Holthofer H, Holmberg C (1994) Pathology of renal arteries of dyslipidemic children with congenital nephrosis. APMIS 102(2):129-134

101. Querfeld U, Kohl B, Fiehn W, Minor T, Michalk D, Schärer K, Müller-Wiefel DE (1999) Probucol for treatment of hyperlipidemia in persistent childhood nephrotic syndrome. Report of a prospective uncontrolled multicenter study. Pediatr Nephrol 13(1):7-12

102. K/DOQI, National Kidney Foundation (2000) Clinical practice guidelines for nutrition in chronic renal failure. Am J Kidney Dis 35(6 Suppl 2):S1-140

\section{Correct answers}
1) $\mathrm{A}$
2) $\mathrm{C}$
3) $\mathrm{B}$
4) $D$
5) $\mathrm{B}$ 